\title{
Difficulties Encountered by Iraqi EFL Learners in Explaining Body Collocations
}

\author{
Dr. Mukhalad Malik / Assist. Lecturer. Aras Abdalkarim \\ Department of English Cihan University/ Sulaimaniya
}

\begin{abstract}
The current paper is concerned with elaborating the difficulties that Iraqi EFL learners may have concerning the knowledge of collocation as a linguistic resource in the learning of English language. In particular, the paper focuses on the linguistic inefficiency that Iraqi EFL learners have when they are required to interpret body- collocations. To verify the efficiency of the collocational knowledge concerning proper explanations of this type of collocation, a test is made to a specific sample of Iraqi EFL learners (Fourth year students/ Department of English/ Cihan University). The data analysis shows that Iraqi EFL learners lack semantic knowledge when they attempt to explain body based collocations. Such semantic knowledge includes specific attributes which the paper aims to illustrate in detail.
\end{abstract}

Key Words: collocations, body collocations, non-literal use, semantic explanation, failure

\section{INTRODUCTION}

Collocations are considered one of the important aspects in English which have received an increased attention in the learning and teaching of English language. In general, collocations refer to a familiar grouping of words, particularly words that appear together and convey meaning by association. I other words, collocations can be defined as "sequences of lexical items which habitually co-occur, but which are nonetheless fully transparent in the sense that each lexical constituent is also a semantic constituent". Fine weather, light drizzle, high winds, and torrential rain are examples of collocation (Cruse, 1986: 40). It has been argued that collocational competence is very important for the process of language production and comprehension as it enables learners to make idiomatic choices as natives do and to process language fluently in real communicative and contextual situations (Ellis et al., 2008). Yet, they are considered problematic area of investigation and one of the problematic phases of collocations lies at the semantic level of language when learners are required to explain certain type of collocations. In particular, the current paper hypothesizes that Iraqi EFL learners have little knowledge of certain type of collocations; body-based collocations, so when they are asked to explain them, they fail to do so and the result is improper explanations represented by explaining them in way that does not match their intended meanings . Hence, the aim is to prove that Iraqi EFL learners lack such semantic knowledge at various levels which the paper try to clarify based on the responses of the learners.

\section{DEFINITIONS AND PROPERTIES OF COLLOCATIONS}

To start with explaining what a collocation is, it is significant to state that there is no total agreement as to the interpretation and understanding of the exact nature of what a collocation is. In its general sense, collocation is "A term used in lexicology by some linguists to refer to the habitual co-occurrence of individual Lexical Items. For example, auspicious collocates with event, sign, etc." (Crystal, 2003: 82). Accordingly, Collocations fall within the scope of syntagmatic lexical relations lexical relation. They are linguistically expected to a certain extent .Some words have no specific collocational restrictions- grammatical words such as the, of, in. By contrast, there are many totally expected limitations, as in eke + out, spick + span. Another important feature of collocation is that they are formal statements of co- occurrence; e.g. green collocates with jealousy (as opposed to, say, blue or red) (ibid: 83). The definition draws the attention to a major point regarding the aspect of collocations; namely, the fact that they have habitual behavior of co-occurrence which means that certain lexical items tend to occur with other lexical items commonly (their occurrence are expectable) in addition to the fact that such occurrence relies on greater probability than mere random choice (Schmitt, 2010: 98). There is, then, a kind of natural combination of words and this combination shows the way that English words are closely associated with each other as when the word 'pay' is usually linked with the word 'attention and the word 'commit' is usually linked with the word 'crime' (O'Dell and McCarthy, 2008: 4). Although a sentence like 'She's got yellow hair' might be understandable to a certain extent, it is not a native sentence, that is, it wouldn't occur in English. Rather, the word 'blonde' is used (collocates) with the word 'hair' to refer to the specific colour (ibid: 6). Schmitt (2010: 103) states that the combinations of certain words 
with (collocations) have certain patterns; unexpected combinations (improper ones) would be judged as wrong or not understandable as with combinations 'go awake' and 'come wrong'. So a major part of collocational definition is the fact that there are certain lexical patterns when combining words together.

\section{LINGUISTIC ANALYSIS OF COLLOCATIONS}

Bartsch (2004: 71) considers that the semantics of a collocation has to be studied under four related aspects: the contribution of the individual constituents to the meaning of the collocation; - the impact of occurrence within a collocation on the meaning of the constituents;- the semantic analyzability of the collocation (transparency of meaning); and the impact of the collocation on the wider context and vice versa. Benson et al. (1986: 254) hold that collocations are transparent in meaning, as opposed to idioms which are held to be fully opaque. They classify different types of multi-word expressions along a continuum of decreasing semantic transparency. However, semantic transparency and opacity are notions that are very hard to capture in operational terms. Not all collocations are equally transparent in meaning. When characterizing collocations in terms of their semantic transparency, there appear to be four possibilities according to Bartsch (2004, 72-75): 1) All constituents of the collocation contribute an aspect of their transparent meaning; the collocation remains semantically fully transparent in the sense that its meaning is constituted of overt realisations of one of the potential senses of each of its constituents. 2) At least one of the constituents of the collocation does not contribute lexical meaning: 3) One constituent may be delexicalised, i.e. lose all or part of its independent meaning, while the other constituent(s) retain their full lexical meaning.

\section{BODY COLLOCATIONS}

Since the paper investigates body collocations, this type is analysed thoroughly to shed lights on their meanings uses and how they function in language relying heavily on previous literature concerned with this specific type of collocations taking into consideration specifically their non-literal uses to verify the hypothesis of the current paper.

\subsection{Body Based Collocations Overview}

Human body vocabulary has always attracted the attention of researchers in the field of semantics. A number of "intralingual" and "inter-lingual" linguistic studies have investigated such terms from a semantic, pragmatic, cultural, and cognitive perspective (Nan, 2012:1033). In general, the semantic aspects of English body parts can express human emotions and feelings or traits of human character. With regard to the language functions, human body collocations and idioms can acquire different (both positive and negative) semantic connotations (non literal or figurative meanings). Stoyanova (2009: 6) divide them into several thematic groups: uman emotions and feelings. Body idioms can be very emotional, they can express emotions such as laughter, cry, moaning as well as delight, happiness, joy (carry sb of his feet, to rub one's hands), love or passion (to win $s b$ 's hand, to offer sb one's hand). On the other hand, body idioms can display a strong resentment, desolation and hopelessness (My foot!', wring one's hand) or feeling of exhaustion and tiredness (to be dead on one's feet, $s b$ 's legs are giving away)Traits of human character. These body idioms are based on positive and negative features of human nature. The concept of laziness can be expressed by folding one's hands, cowardice can be mocked at by an expression such as get cold feet, while bravery can be admired by to get oneself in hand. The ability to react quickly while being permanently active can be highlighted by expressions such as think on one's feet or be a firm hand. To show psychological stability, an idiom such as to find one's feet or to be on one's feet can be used. Similarly, special professional skills or experience can be rendered by somatisms such as be an old hand, a fresh hand or be all thumbs. Such groupings clearly illustrate that body based collocations can have both literal and non-literal when used in a language but the difference between the two is not always manifested easily. In many cases, it is the comprehensive knowledge of the very specific meaning of the collocation used in a certain context which can clearly elaborate the way in which the body based collocation is used (Wilkinson, 1991: 533)

\subsection{Body Based Collocations of Non- Literal Uses}

As has been mentioned earlier, the type of the body collocation that is going to be analysed and investigated thoroughly is - transparent, i.e. those which refer to non-literal uses. First of all, it is significant to recall (as explained in 3.2) that when using a body based collocation in a certain communicative situation or in any other related context, one of the collocates retains its literal meaning and the other indicates a non-literal one but the result of such collocations will be entirely of non-literal use. It is totally familiar that in the majority of languages body-part words appear in collocations denoting various meanings and ideas. It is possible to state that the non-literal use of body based parts is derived from a number of factors where it is plausible to state that they are (their non-literal use) partly based on genuine physical features, partly on convention, partly on imagination, and, moreover, their universal and cultural aspects are intertwined (Aitchison, 2012: 188-189). 
When analyzing body based collocations which carry non-literal use, it is very important to state the fact that the human body has a significant role in the lives of human concerning enriching the figurative (non-literal) thinking and, thus, it is to be considered a bountiful source for language. But such consideration is based on the fact that most body parts refer both to function and appearance. Manerko (2014: 203) classify body parts of non-literal uses into what he calls container image schema as in the following:1) In the first group of combinations elements head, eye(s), nose and mouth are viewed as holding things inside them. In this case, a virtual boundary represented by the preposition in helps to distinguish a body part (eyes, nose, mouth) as a conceived entity. For example, in the English idiom have eyes in one's head means "to be observant; be able to notice one's surroundings, what somebody is doing" eyes are singled out for primary focal prominence. 2) Containers may be open or closed if the action denoted by a verb is aimed at extracting some restricted inherent subpart of the perceived surface of a container. It may be represented by the following example: And then I'll be good and not open my head again, in which the phrase to open one's head corresponds to the idea of talking too much revealing one's thoughts. In the second sentence Everything I say is wrong this morning. I'm frightened to open my mouth the expression to open one's mouth means "to say something, the implication often being that somebody speaks too readily or indiscreetly". The difference between to open one's head and to open one's mouth is associated with the positive in the first case and positive or negative evaluative connotation in the second phrase.

\section{PROCEDURES AND DATA ANALYSIS}

As mentioned in the very beginning of this paper, to verify the hypotheses, a test (Appendix 1) is conducted on twenty learners (chosen arbitrarily) majoring English as a foreign language in the Department of English $\left(4^{\text {th }}\right.$ level)/ Cihan University/ Sulaimaniya/ for the academic year 2015-2016. The reason behind choosing $4^{\text {th }}$ year stage students is the fact that they are supposed to have been exposed to both the knowledge and the use of language so they have at least the minimum required knowledge of how to interpret body based collocations of non-literal use. The test is a group of sentences which includes the body based collocation (as mentioned previously, those items are taken from O'Dell and McCarthy (2008) with certain modifications so as to suit the purpose of the test). Learners are asked first to read the sentences carefully ( 2 minutes for each sentence) and then are asked to write down in detail what the underlined mean. If the learner interprets the given collocation non-literally with its exact meaning (or close to the exact meaning; giving an idea of what it means) then she/ he is given a full mark. If the learner interprets the given collocation literally or non-literally but with a completely different meaning then the response is considered wrong. Finally, with each type of semantic failure, a table is given to show the percentage of such failure*. *The method of correction and the statistical procedures are recommended and supervised by Professor Dr. Obeid AL-Zoubaiay/ College of Business Administrative and Finance Science/ Cihan University/ Sulymanyhai

\subsection{Semantic Failure Due to Literal Interpretations}

Within this semantic type of failure, learners explained the body part of the given collocation literally (what it exactly refers to); their semantic knowledge is confined to explain the body part as it means not as being part of a collocation with a non-literal use. The learners explained the part of the collocation (which is the body part) as it refers to along with the other parts of the given collocation (the other word or words that are part body part collocation). Such improper explanation shows that they are entirely not aware that the body part within the given collocation has a meaning beyond its literal use or they tend to rely on explaining the other collocate majorly and then join it with the literal explanation of the body part. In both cases, the entire meaning of such an explanation is improper and irrelevant to the exact meaning. To illustrate this type of failure, the following responses can be considered:Ex (1) "it is the bill that have made by the company which contains the name of the foot". This response shows clearly that the learner explains the collocation literally; he approaches explaining the body based collocation by first relying on the collocate 'bill' and, thus, the focus is on 'bill' rather than 'foot' as the former has a clear literal meaning (a printed paper which shows an amount to be paid). So the ultimate explanation is a bill that contains something and not the fact that 'foot' means 'pay'. Ex (2) "keeps Jana of standing....."Ex (3) "save Jana on her toes...."The examples above show that the learners focused on the literal interpretation of "toes" which is semantically associated with standing. Thus, the explanation is directed to show the physical idea of standing rather than explaining the body collocation "to keep Jana on her toes" as staying active and focus which is the proper meaning.Ex (4) "Here this line talks about Gina's eye that you can understand everything in Gina's eye". This response deals with explaining the body collocation "has an eye for" which carries the non-literal meaning of being a good observer or to have the ability to notice in detail while the response shows that the learner focused on the concept of 'eye' physically. Consequently, the leaner explained the use of 'eye' literally as to look at someone's eye to understand and not to relate the use of 'eye' with the proper meaning of being a good observer. Ex (5) "Gina keeps watching for detail". This is another example which clearly shows the improper explanation of the body based collocation due 
to considering it literally; the learner explained the collocation according to the literal sense that it implies "an eye" and, thus, neglecting the non-literal sense which indicates the meaning of having good sense of noticing things in detail and not having the physical aspect of watching. In other words, the learner explained the concerned collocation literally when he, apparently, associates the word 'eyes' with the physical aspect of its function which is looking at things and not explaining it as part of being able to notice things carefully and efficiently. Since the main focus of this paper is on this precise aspect of semantic inefficiency concerning the improper explanation of body based collocations of non-literal sense, more responses which show this kind of failure are analysed and explained in details:Ex (6) "means hand in hand someone into another".This collocation "hand in hand" is totally explained as having hands together (like shaking hands" when the learner uses the word 'someone' he is directly referring to the physical aspect of using a hand and that more than one person is involved. Once again, the learner thought of the collocation as referring to its literal sense and not to what is beyond: hand in hand does not mean the use of hands physically but the fact that two things happen at the same time.

Ex (7) "They are in agreement".

The use of the word "agreement" clearly shows that there are two or more persons who have agreed or had an agreement as the use of this particular word requires the physical use of hands (shaking hands) when people agree on something. This could be repeatedly attributed to the literal interpretation of the concerned collocation and not recognizing that it is explained as not involving the use of hands but the use of what 'hand in hand' refers to.The following table illustrates the percentages of failures due to this factor:

Table 5: Semantic Failure Due to Literal Interpretation

\begin{tabular}{|l|l|}
\hline Item NO. & Percentage \\
\hline 1 & $2 . \%$ \\
\hline 2 & $0 \%$ \\
\hline 3 & $12 \%$ \\
\hline 4 & $9 \%$ \\
\hline 5 & $3 \%$ \\
\hline Total & $\mathbf{2 6 \%}$ \\
\hline
\end{tabular}

\subsection{Semantic Failure Due to Improper Non-literal Interpretation}

In many cases, learners explained the given collocations relying on non-literal sense but the explanation did not match the proper meaning. In other words, although they recognized that such collocations are used in a non-literal sense, they explained them referring to other meanings and interpretations which do not match their intended meanings. So the result is a non-literal explanation but it does refer to what the collocation exactly means. To illustrate this point in detail, the following examples can be considered:Ex (8) "It mean care the blame"Regardless of the grammatical aspect of language, this collocation "shoulder the blame" is interpreted in a non-literal sense but in a way that doesn't mean at all the exact meaning "to take responsibility of some action or deeds". "care the blame" doesn't refer to what this type collocation means and, moreover, it is interpreted ambiguously. Ex (9) "in that sentence sue decided to explain the problem and fix the whole problem"It is obvious that there is recognition of the learner that the collocation has a non-literal sense; yet, the interpretation is not to be taken as explaining or fixing the problem as it does not convey the exact meaning of the collocation. Ex (10) "have someone who telling her whatever she wants" This clearly shows that the interpretation of the collocation "has an eye for" is taken to be in non-literal use as opposed to a literal one. However, it does not mean what the collocation actually means; 'an eye' is interpreted as to have a person who tells Gina everything (as a kind of spy or some acquaintance). While the intended meaning is being good at noticing, the learner's response suggests a rather different meaning which is not even close to the exact one. Ex (11) "hand in hand means that someone who doesn't have any source of money"This is clearly associated with the idea of unemployment. Although it is interpreted non-literally, it refers to being unemployed and having no money while the exact meaning refers to something else; happens at the same time. Ex (12) "having three sons means that Jana is appear as a young person in the family". Again, the response shows clearly that the learner recognizes that "on her toes" are not to be taken literally but he expresses another meaning which totally not related to the exact one. The learner talks about the idea of being young; there is a description of a member of a family which doesn't match the exact meaning to be conveyed. Ex (13) "This is a great family and they are having nice life". While the interpretation goes beyond the literal sense, the response clearly shows that the learner is drifted away when attempting at interpreting the concerned collocation and, thus, the result is an interpretation which does not match the intended one. This is because the learner could have thought of other words within the given sentence and thus he/she focused on certain lexical items rather than considering the entire sentence as one unit. The following table illustrates the percentages of failures due to this factor: 
Table 6: Semantic Failure Due to Improper Non- Literal Interpretations

\begin{tabular}{|l|l|}
\hline Item NO. & Percentage \\
\hline $\mathbf{1}$ & $\mathbf{1 \%}$ \\
\hline $\mathbf{2}$ & $\mathbf{3 \%}$ \\
\hline $\mathbf{3}$ & $\mathbf{9 \%}$ \\
\hline $\mathbf{4}$ & $\mathbf{9 \%}$ \\
\hline $\mathbf{5}$ & $\mathbf{6 \%}$ \\
\hline Total & $\mathbf{2 7 \%}$ \\
\hline
\end{tabular}

\subsection{Semantic Failure Due to Total Lack of Linguistic knowledge}

In some cases, learners show total lack of linguistic knowledge concerned with interpreting the required body based collocation of non-literal use. This lack of knowledge is to be considered a severe one as they did not interpret anything; they wrote nothing. When asked about it, learners attributed their failure to the fact that they didn't know what the given collocations mean at all. The responses of the learners as far as this type of failure is concerned are reflected by a number of linguistic forms including not writing anything (no response at all) and, in some cases, one word only as in 'increased' 'family' and so on. The total percentage of this type of failure is $16 \%$. This linguistic attribute cerates additional and serious problem as far as ELT is concerned and as far as the linguistic input is concerned where competence, in this specific aspect, is entirely deemed awkward, hesitant and not reliable at all.

\section{CONCLUSION}

Body based Collocations of non-literal use are specific type of collocations that have certain communicative functions of different values and at different levels. Unfortunately, Iraqi EFL learners face many difficulties while trying to interpret them in a certain communicative situation due to certain semantic attributes which lead to improper interpretation and may, consequently, lead to the collapse or misunderstanding of the whole communication process. Such semantic failures include not being able to recognize the fact that such collocations are used beyond their literal sense and they mean things not physical, rather, figurative or nonliteral. In addition, where a non-literal interpretation is achieved, learners show lack of what those collocations mean in reference to their given situations; although recognizing that they are used non-literally, they couldn't recognize what they exactly mean. The most important thing to be stated is the fact that learners need to know about the use of language rather than knowledge which is gained in a way or another. Indeed, body based collocations of non-literal use can greatly improve thought process and will certainly lead to a better and an effective communication. Text designers and those who are in charge of various syllabuses should consider concentrating on the use of language and not only its grammatical or syntactic levels. They should include who language is used at various levels and at different spoken and written situations. Learning collocations in general and body based ones in particular are of great value if a better and an efficient communication is to be achieved. In fact, it is through the acquisition of this type of collocation (along with other various types) learners can enhance the skills of vocabulary as well as gain knowledge on how English is structured which are significant in ELT.

\section{REFERENCES}

[1] Aitchison, J. (2012). Words in the Mind: An Introduction to the Mental Lexicon. London: Wileylackwell.Bartsch, S. (2004). Structural and Functional Properties of Collocations in English: A corpus study of lexical and pragmatic constraints on lexical co-occurrence. Dischingerweg: Gunter Narr Verlag Tübingen.

[2] Benson et al. (1986). Lexicographic Description of English. Studies in Language Comparison Series. Amsterdam, New York, John: Benjamins Publishing Company.

[3] Cruse, D. A. (1968). Lexical Semantics. Cambridge: Cambridge University Press.

[4] Crystal, David. (2003). A Dictionary of Linguistics and Phonetics. Oxford: Blackwell.

[5] Manerko, L. (2014). From Human Body Parts to the Embodiment of Spatial Conceptualization in English Idioms. Selected Papers from the 4th UK Cognitive Linguistics Conference. Moscow Lomonosov State University.

[6] Nan, J. (2012). Conducting Reaction Time Research in Second Language Studies. New York : Routledge.

[7] O’Dell, F. and McCarthy, M. (2008). English Collocations in Use Advance. Cambridge: Cambridge University Press.

[8] Schmitt, N. (ed) (2010). An Introduction to Applied Linguistics. London: Hodder Education.

[9] Stoyanova, Inga. (2009). "Semantic Aspects of English Body Idioms.” Diss. IRIM Chisinau. 
[10] Wilkinson, K. J. (1991). Studies in the Semantics of Generic Noun Phrase. Amherst: Reproduced and distributed by Graduate Linguistic Student Association, Dept. of Linguistics, South College, University of Massachusetts.

\section{Appendix 1}

Read the following sentences carefully and then explain the underlined:

1. Although others were also responsible for the problem, Sue decided to shoulder the blame.

2. Choose what you like from the menu- the company is footing the bill.

3. Having three sons under the age of five Keeps Jana on her toes.

4. Gina has an eye for detail so ask her to check the report.

5. Unemployment goes hand in hand with the social unrest.

\section{Key Answers}

\begin{tabular}{|l|l|}
\hline Collocation & \multicolumn{1}{c|}{ Meaning } \\
\hline shoulder the blame & take responsibility for something bad \\
\hline foot the bill & Paying \\
\hline keep someone on their toes & makes someone stay active and concentrated \\
\hline have an eye for & is good at noticing \\
\hline go hand in hand with & happens at the same time or as a result of \\
\hline
\end{tabular}

